Running head: Influence of built environment on pedestrian's crossing decision

To cite this paper: Granié, M. A., Brenac, T., Montel, M. C., Millot, M., \& Coquelet, C. (2014). Influence of built environment on pedestrian's crossing decision. Accident Analysis \& Prevention, 67, 75-85. doi: http://dx.doi.org/10.1016/j.aap.2014.02.008

\title{
Influence of built environment on pedestrian's crossing decision
}

Marie-Axelle Granié* ${ }^{1}$, Thierry Brenac ${ }^{1}$, Marie-Claude Montel $^{1}$, Marine Millot ${ }^{2}$, Cécile Coquelet $^{1}$

${ }^{1}$ IFSTTAR-LMA, 304 Chemin de la Croix Blanche, F-13300, Salon-de-Provence, France

${ }^{2}$ CETE Méditerranée, Pôle d'activités Les Milles, Avenue Albert Einstein, 13593 Aix-enProvence Cedex 3

* Corresponding author

marie-axelle.granie@ifsttar.fr

Tel : +3349057 7979

Fax : +33490568618 


\title{
Influence of built environment on pedestrian's crossing decision
}

\begin{abstract}
The objective of this experimental study is to identify the differentiation made by pedestrians, in their crossing decision, between various urban environments, notably in terms of perception of walking pleasantness and safety. This experiment further aims to identify the environmental features that pedestrians take into account and the inferences they develop and use to explain their road crossing decision. Sets of photographs presenting five different environments (city center, inner suburbs, public housing in the outskirts, commercial zone in the outskirts and countryside) were presented to 77 participants divided up into three age groups (pre-adolescents, young and middle adults). Their decision to cross or not, their perception of pleasantness and safety, and the elements they take into account to make a decision were collected for each environment presented. The quantitative results show the pedestrians' perceptions of the pleasantness and safety of public spaces, in terms of walking, largely vary with urban environments. Moreover, the crossing decision significantly varies according to the environment. Pedestrians were significantly more inclined to take the decision to cross in city center than in the other sites presented. The qualitative analysis of the interviews shows that the presence and function of the buildings, the quality of the sidewalks and the marked parking spaces are key factors to explain their crossing decision, by enabling them to infer the density of pedestrians and traffic and the vehicle speed.
\end{abstract}

Keywords: Pedestrian - Perception - Road crossing decision - Built environment 


\section{Influence of built environment on pedestrian's crossing decision}

\section{Introduction}

Providing urban spaces that benefit to all users is a major challenge for urban designers and planners. This concern requires to deal with roadway, roadside and road environment. Such approaches need knowledge on the influence of environment characteristics on users' trips. Concerning pedestrians, the relation between built environments (street network, land use) and walking or pedestrian flow has been widely studied (Baranes et al., 2005; Marshall and Garrick, 2010; Mitra et al., 2010; Shay et al., 2006). It has also been established that the frequency and seriousness of pedestrians accidents vary with urban density, the function of the zone (residential, business activities), presence of shops, or location in the city (city center, suburbs) (Clifton et al., 2009; Dissanayake et al., 2009; Graham and Glaister, 2003 ; Wedagama et al., 2006). Of course, these differences come in part from the influences of the environment on important parameters such as the speed of vehicles, that increases the risk and seriousness of accidents (Aarts and Van Schagen, 2006; Davis, 2001; Pitt et al., 1990; Rosén et al., 2011).

The differentiated effects of urban spaces on pedestrian accidents may also, at least in part, be due to pedestrians' perception and interpretation of the environment and their influence on crossing decisions. Thus, the design and layout of the public space of some built environments (in terms of road accessibility, roadway width, salience of the car in a public space, which is notably influenced by the organization of parking) may poorly match the pedestrians' uses and perceptions of this space (high pedestrian mobility, strong sense of ownership of public space by the inhabitants, very young population). Such a mismatch can lead to a lack of safety for pedestrians (Millot, 2008).

Pedestrians' perceptions of the road environment have been studied by psychologists, with a view to improving risk evaluation (Cho et al., 2009; Mullan, 2003; Underwood et al., 2007), and by urban planners, architects and geographers, with a view to make this environment more favorable to pedestrian (Foltête and Piombini, 2007; Hine, 1996; Livi Smith, 2009) in terms of the feeling of comfort, safety and security. Some of these studies, such as the one by Ewing et al. (2006) dealt with the "walkability" or "walking potential" of public space - i.e. the way individuals perceive and assess the street as a walking space. This study looked into the physical elements in the environment that determine the qualities of the urban design (recognizable, readable, open, on a human scale, transparent, unified, rich, coherent and in 
good upkeep) and can influence perceptions and subjective reactions of pedestrians (feeling of safety or comfort, level of interest). All these studies provide a better understanding of the environmental determinants of pedestrian mobility.

However, the way in which the built environment influences (or does not influence) pedestrian behavior in interaction with other types of users, notably when crossing a street, is not taken into account for now. To the best of our knowledge, no research has yet been carried out to explore the influence of context - and especially road scenes and their representation by the pedestrian - on the pedestrians' expectations and decision making of, as it has already been done for drivers (Fleury et al., 1991). Thus, the previous studies on pedestrians do not enable to determine whether perception and interpretation of urban environments by pedestrians lead them to develop expectations on how the current situation will evolve (notably in terms of foreseeing driver behavior) so as to be able to take faster, better suited decisions when they are faced with a crossing task. Recent work suggests that the environment influences the crossing task through its topographical, infrastructural and regulatory aspects (Bergeron et al., 2008; Chu et al., 2004; Li et al., 2010). Other physical elements in the environment, however, such as the nature and spatial distribution of buildings, pedestrian and traffic density, could influence the gathering of information on the crossing situation and its interpretation, notably concerning inferences on driver behavior (Foot et al., 2006), as well as decision-making when crossing. Empirical evidence on these subjects is likewise limited and a better grasp of the "crossability" of urban environments is needed, in order to act more effectively in terms of prevention, but also of road engineering. The goal of the present study is to explore the nature of perceptions of the built environment of crossing - both in terms of general feeling (pleasantness, feeling of safety) and in terms of road potentiality to be crossed - and their mobilization by the pedestrians when crossing. The hypothesis is that the presence of a number of elements in the environment - and their type will influence the information taken in the situation of crossing and the crossing decisionmaking. It is furthermore assumed that taking into account the elements of the environment requires a conceptual organization (Dubois et al., 1993) in the pedestrian and that it is built by the displacement activity, social interaction, and regular perception of road scenes in the various activities of travel (Van Elslande, 2001). Thus, this conceptual organization depends on the level of experience of the individual concerning the road and its functioning, both as a pedestrian and as a driver.

Given that this field is still little investigated, this research aims: (i) to study the differentiation made by pedestrians between various urban environments, notably in terms of 
perception of pleasantness and safety (for walking); (ii) to explore the influence of the environment of the crossing site on the crossing decisions of pedestrians, and further to identify the environmental features that pedestrians take into account and the inferences they develop and use when they explain their road crossing decision; and (iii) to examine the effects of the pedestrian experience of participants, but also of their driving practice, on such perceptions and decisions. This study is a first investigation of the role of the environment in the pedestrian's decision to cross in general. The pedestrians aged over 65 were not included, despite their greater risk of accidents (ONISR, 2011), due to the particularities of this age group, particularly in terms of functional limitations (Dommes et al., 2013).

\section{Method}

\subsection{Material}

In a preliminary focus group study, 20 photographs of built environments were presented to participants in order to gather their perceptions related to the agreement and convenience of these environments for walking and crossing (Granié et al., 2013). The results of this qualitative study allowed to identify, among these various environments, five main types of urban environments, contrasted in terms of perceptions and inferences made by the participants. The following features were used by the participants of the preliminary study to characterize these types of environments:

- $\quad$ city center environment: wide sidewalks, narrow roadway, demarcation between the sidewalk and the road, commercial activities generating walking but also sojourning of pedestrians, presence of trees;

- $\quad$ inner suburb environment: heterogeneous but continuous buildings, straight alignment of the sidewalk, old and recent housing, some commercial activities;

- public housing environment in the outskirts: parking at the bottom of the buildings, high multi-dwelling buildings, no building continuity, homogeneity of the frame, unclear demarcation between public space and private areas, wide road and wide field of view;

- commercial zone in the outskirts: recent business buildings on the outskirts of the town, wide road, narrow sidewalks, parking spaces;

- countryside environment: few houses, presence of through-traffic, no commercial activity, no sidewalk, abundant vegetation.

For the present experiment, five sites meeting the above-mentioned criteria were selected in different urban regions of the South East of France and were chosen to be unfamiliar to the 
participants. The experimental material used five sets of five photographs, each of these sets presenting one of these environments (see an example in figure 1). Each set, presented on a 297x420 mm (11.69x16.54 in.) page, showed left-hand, right-hand and central views of a site, thus providing a $180^{\circ}$ view of a street. These photographs were taken from the pedestrian's point of view (height of the view and position on the sidewalk in a pre-crossing position). The photos were taken under normal and daily conditions of use, during working hours but outside rush hours, in order to control the situation presented and avoid overloaded situations that would overly focus the participants' attention (oncoming vehicles located right next to the viewer, for example) and may influence their perception more than the environment. The situations of crossing in each presented environment were similar: a two-lane infrastructure environment (one lane in each direction), no visible marked crosswalk within 50 meters. In French law, pedestrians are required to cross the road on a marked crosswalk when there is one less than $50 \mathrm{~m}$ (54.68 yds.) from them. In the other cases, they can cross the road while taking into account the visibility, the distance and speed of the vehicles. According to the French law, driver must yield to pedestrians starting to cross or indicating their intention to cross. Thus, crossing the road requires interactions with drivers in any cases. As there was no marked crosswalk less than $50 \mathrm{~m}$ from the crossing sites studied, the participants had not to refer to the rules related to such a marking when they decided to cross or not. On each left-hand view and in all cases, an approaching vehicle was visible, the same one at the same distance from the pedestrian's point of view. The legal speed limit was 50kph on all urban sites, and 90kph on the site in countryside environment (this information was not given to the participants). However, as the experiment aimed to show whether the environment influences the decision to cross or not, the information related to the vehicle (type, position) had to be the same for the 5 various environments presented, so that the participants' inferences on the current uses of public space, the driver's behavior and interactions between vehicle and pedestrian could only depend on information from the environment..

The position of the vehicle (distance from the point of view of the pedestrian) was thus fixed in order to avoid to generate an excessive predominance of positive (or negative) crossing decisions, both in relation to previous findings published in the scientific literature (Lobjois and Cavallo, 2007) and to the results of an initial pre-test which compared responses with vehicles in various environments at distances of $20 \mathrm{~m}, 25 \mathrm{~m}, 30 \mathrm{~m}$ and $35 \mathrm{~m}$ from the pedestrian. Finally, the vehicle was placed at the distance of $35 \mathrm{~m}$ (38.28 yds.) since the pretests showed that very few positive responses (decision to cross) were obtained for shorter distances, whatever the environment. 


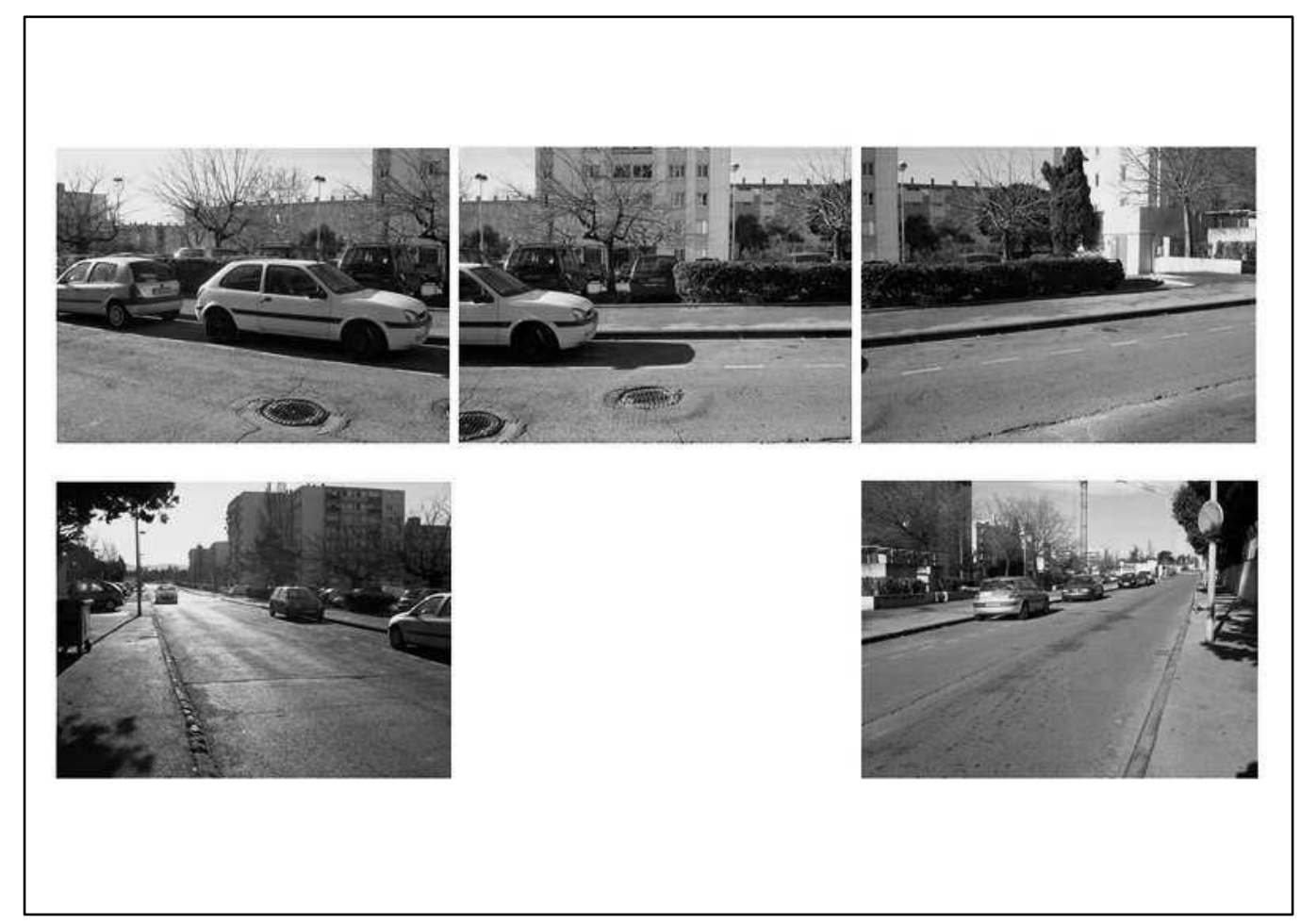

Figure 1. Example of a set of photographs. Environment characterized as public housing environment in the outskirts

\subsection{Participants}

In all, 77 participants (46 males and 31 females) from the South-East of France took part in this experiment. With the aim of studying the effects of experience as a pedestrian and as a driver on the decision to cross and the information collected and induced from the environment, three groups of participants were compared:

- 26 pre-adolescents ( 15 boys and 11 girls, from 10 to 14 years old, mean $=12.2$ ). They are used to walk on their own, without adult, and aren't used to drive motorized vehicle;

- 26 young adults (18 men and 8 women, from 18 to 24 years old, mean $=19.3$ ) at the end of their driving training;

- 25 middle adults (13 men and 12 women, from 25 to 63 years old, mean = 37.2), experienced drivers with over 5 years of driving license.

The interviews with the children took place in their secondary school, with the agreement of the school management and of the parents of children contacted. The children received a gift after the end of the interview (road safety education books). The interviews with adults 
(young and middle) were conducted in the research laboratory. The adults received compensation of $€ 45$ for their participation.

\subsection{Procedure}

The five sets of photographs were presented one after the other, in a random order, to each participant. The participants were asked to assume they had to go to the other side of the road. No other detail on the conditions of their trip was given to the participants. For each environment, the question was: "In this environment and this situation, do you cross the road or not?"

The five sets of photographs were then presented once again, one by one in the same order, and the participant was asked to explain why she/he decided to cross or not to cross in this environment. The next questions posed to the participant were only snapbacks from her/his responses, if possible using the same expressions used by the participant, using the Piaget's technique of clinical interview (Opper, 1977). The same type of questions was used for the three groups of participants. Three lines for questioning were covered:

- $\quad$ clues used by the participant to describe or identify the environment;

- $\quad$ inferences made by the participant about the driver's behavior, in direct connection with decision making;

- elements of the environment, perceived or inferred, taken into account by the participant and allowing these inferences.

At the end of the interview, the participants were also asked to say to what degree they would find it pleasant to walk in each of the environments presented. They estimated the degree of pleasantness by putting a mark on a non-graduated 10 centimeter-long scale from "not pleasant at all" (scored as 0 ) to "very pleasant" (scored as 10). In the same way, they were asked to say to what extent they would find it safe to walk in the environment presented, by putting a mark on a non-graduated 10 centimeter-long scale from "not safe at all" (scored as $0)$ to "very safe" (scored as 10). Each interview lasted 30 minutes on average.

\section{Quantitative analysis}

Data processing included $(i)$ a quantitative analysis of the effect of the site on the pleasantness and feeling-of-safety scores, (ii) a quantitative analysis of answers in terms of crossing decision obtained (yes/no), and (iii) a qualitative content analysis of verbal responses obtained during the interview from participants to explain their decision in each environment. 


\subsection{Degree of Pleasantness and Feeling of Safety}

The dataset contains, for each of the 77 participants of the total sample, a pleasantness score and a feeling-of-safety score (ranging from 0 to 10) for each of the five environments. Only the overall results for the 77 participants taken as a whole are presented here, since no noticeable or statistically significant difference was found between the three groups of participants as regards the scores obtained, whatever the environment considered (detailed results for each group of participants can be found in Montel et al., 2013). The mean pleasantness and feeling-of-safety scores are given in table 1, with the $95 \%$ confidence intervals of these estimates.

\begin{tabular}{lccccc}
\hline & $\begin{array}{l}\text { Countryside } \\
\text { environment }\end{array}$ & $\begin{array}{c}\text { Commercial } \\
\text { zone } \\
\text { environment } \\
\text { (outskirts) }\end{array}$ & $\begin{array}{c}\text { Public } \\
\text { housing } \\
\text { environment } \\
\text { (outskirts) }\end{array}$ & $\begin{array}{c}\text { Inner } \\
\text { suburb } \\
\text { environment }\end{array}$ & $\begin{array}{c}\text { City center } \\
\text { environment }\end{array}$ \\
\cline { 2 - 6 } Pleasantness & 5.12 & 2.98 & 3.96 & 4.90 & 8.38 \\
$\begin{array}{l}\text { score } \\
\text { (95\% CI) }\end{array}$ & $(4.36 ; 5.89)$ & $(2.53 ; 3.43)$ & $(3.42 ; 4.50)$ & $(4.41 ; 5.39)$ & $(8.05 ; 8.70)$ \\
$\begin{array}{l}\text { Feeling-of- } \\
\text { safety score } \\
(95 \% \text { CI) }\end{array}$ & $\begin{array}{c}2.13 \\
(1.60 ; 2.65)\end{array}$ & $\begin{array}{c}3.99 \\
(3.48 ; 4.50)\end{array}$ & $\begin{array}{c}4.97 \\
(4.42 ; 5.52)\end{array}$ & $\begin{array}{c}5.76 \\
(5.28 ; 6.23)\end{array}$ & $\begin{array}{c}8.12 \\
(7.75 ; 8.49)\end{array}$ \\
\hline
\end{tabular}

Table 1. Mean pleasantness scores and feeling-of-safety scores (with 95\% CI) $(n=77)$

The test of a significant difference among the sites was carried out using the Friedman test, which makes it possible to take into account the fact that data are paired (each participant gave five scores, one per site). For the pleasantness score as for the feeling-of-safety score, a low $p$-value is obtained which suggests that there are highly significant differences between the environments presented, both from the pleasantness and feeling-of-safety points of view (Friedman $\mathrm{Chi}^{2}$ of 143.8 and 152.5 respectively, with 4 degrees of freedom; p-values $<10^{-15}$ in both cases).

Overall, the degree of pleasantness of the environment (for walking) was rated high for the city center site, medium for the inner suburb and countryside sites, and low for the sites located in the outskirts (commercial zone and public housing environments). As regards the feeling of safety, it was rated high for the city center site, medium for the inner suburb and public housing sites, and low for the countryside and commercial zone sites. 


\subsection{Environments and Pedestrian Crossing Decision}

For each environment presented, participants were asked to say whether, in such conditions, they would have taken the decision to cross the roadway, or not. Thus, the response variable is binary. A logistic regression was carried out in order to relate this binary response to the variables of the experiment: the variables SITE and GROUP. The variable SITE corresponds to the site presented (countryside environment, commercial zone environment in the outskirts, public housing environment in the outskirts, inner suburb environment, and city center environment). The variable GROUP represents the group of participants (middle adults, young adults, pre-adolescents).

The data obtained, however, are clustered, since each participant gave five responses (one per site). Given the number of participants $(77)$, the dataset contains $385(77 \times 5)$ observations grouped into 77 clusters. Applying ordinary logistic regression to these data would imply to neglect the intra-cluster correlation, which could lead to under-estimate the standard errors on the coefficient estimates (Ananth et al., 2005). In such situations, applying a random intercept logistic regression model is preferable. A random component of the intercept, $a_{i}$, depending on the cluster $i$ (participant), is added to the usual regression formula, which becomes $\alpha+a_{i}+\Sigma \beta_{j} x_{i j}$, where the $a_{i}$ 's are assumed to follow a normal distribution $\mathrm{N}\left(0, \sigma^{2}\right)$. The $a_{i}$ 's take into account a participant-specific effect. The parameter $\sigma^{2}$ is to be estimated, in addition to the usual estimation of the fixed effects $\left(\beta_{j}\right)$ and the constant $\alpha$.

Beyond the constant term and random effect (random intercept), the model adjusted includes the variables SITE and GROUP. The estimates of the fixed-effect coefficients of the model are given in table 2 . The estimate of the random effect parameter $\left(\sigma^{2}\right)$ is 1.86 . The categories "middle adults" and "countryside environment" are taken as levels of reference for the variables GROUP and SITE respectively, which means that their effects are contained in the value of the constant $\alpha$. The log-likelihood of this model (-159.0) appears as significantly higher than that of the model reduced to the constant term and random effect (-246.2). The pvalue of the likelihood ratio test is very low $\left(p<10^{-15}\right)$. 


\begin{tabular}{lcll}
\hline Fixed-effect parameter & Estimate & Standard error & $p$-value (Z-test) \\
$\alpha$ (constant) & -2.30 & 0.53 & $0.1510^{-4}$ \\
$\beta_{\text {SITE-commercial-zone-outskirts }}$ & 0.14 & 0.55 & 0.80 \\
$\beta_{\text {SITE-public-housing-outskirts }}$ & 1.73 & 0.49 & $0.3910^{-3}$ \\
$\beta_{\text {SITE-inner-suburbs }}$ & 0.74 & 0.52 & 0.15 \\
$\beta_{\text {SITE-city-center }}$ & 5.70 & 0.65 & $<10^{-15}$ \\
$\beta_{\text {GROUP-young-adults }}$ & -0.87 & 0.56 & 0.12 \\
$\beta_{\text {GROUP-pre-adolescents }}$ & -0.27 & 0.54 & 0.16 \\
\hline
\end{tabular}

Table 2. Estimates of the fixed-effect parameters for the random intercept logistic regression model including the variables SITE and GROUP

The $\beta_{j}$ 's can be interpreted as log-odds-ratios. As regards the effects of the environment, the coefficients corresponding to the public housing environment in the outskirts and to the city center are positive and significantly different from zero. This means that these environments significantly contribute to increase the probability of a decision to cross the roadway, as compared to the reference category (countryside environment). It appears that the coefficients of the variable GROUP are not significantly different from zero. Moreover, this variable does not contribute significantly to the model: applying a likelihood ratio test to this model compared to a model including only the constant term, random effect, and variable SITE leads to a $p$-value of 0.29 , which is not significant at the 0.05 level.

Therefore, the model only including the constant term, random effect, and variable SITE seems more relevant. It gives nearly exactly the same coefficient estimates, for the variable SITE, as those given in table 2. The contribution of this model, as compared to the model reduced to the constant term and random effect, is statistically significant (log-likelihood = 160.3; likelihood ratio test: $p<10^{-15}$ ). The practical outcomes of the model are the probabilities of a decision to cross the roadway, for an average individual $\left(a_{i}=0\right)$, as a function of the variables of this model (here, the variable SITE). These modeled probabilities and their $95 \%$ confidence intervals are given in table 3.

\begin{tabular}{lccccc}
\hline & $\begin{array}{c}\text { Countryside } \\
\text { environment }\end{array}$ & $\begin{array}{c}\text { Commercial } \\
\text { zone } \\
\text { environment } \\
\text { (outskirts) }\end{array}$ & $\begin{array}{c}\text { Public } \\
\text { housing } \\
\text { environment } \\
\text { (outskirts) }\end{array}$ & $\begin{array}{c}\text { Inner } \\
\text { suburb } \\
\text { environment }\end{array}$ & $\begin{array}{c}\text { City center } \\
\text { environment }\end{array}$ \\
Probability & 0.06 & 0.07 & 0.28 & 0.12 & 0.95 \\
$(95 \%$ CI) & $(0.03 ; 0.14)$ & $(0.03 ; 0.15)$ & $(0.17 ; 0.41)$ & $(0.06 ; 0.22)$ & $(0.88 ; 0.98)$ \\
\hline
\end{tabular}

Table 3. Probabilities of a decision to cross the roadway, as estimated by the random intercept logistic regression model including the variable SITE 
Overall, the probability that participants answer that they would have decided to cross, in the environment and conditions presented through the photographic material, appears to be very high $(0.95)$ for the city center environment, moderate $(0.28)$ for the public housing environment in the outskirts, and low (from 0.06 to 0.12 ) for the other environments presented.

Alternative models were also tested, by replacing the variable SITE with the above-mentioned pleasantness score and feeling-of-safety score. Thus, these models included these scores, the constant term, and random effect. The aim was to evaluate to what extent the perceived pleasantness and feeling of safety (for walking) in these environments could be sufficient to explain the responses in terms of crossing decision. Different models were tested depending on the scores taken into account (agreement score, feeling-of-safety score, or both) and depending on the way each score was included in the model: in the original form of the score (continuous variable, bounded interval), in the form of a logit function of it, or in a discretized form (ten-level factor, or two-level factor). Overall, although these alternative models are better than the model reduced to the constant term and random effect, they are clearly less satisfying (log-likelihoods ranging from -210.3 to -186.4) than the model including the constant term, random effect, and variable SITE (log-likelihood $=-160.3$ ). This loss in likelihood is not compensated by a corresponding reduction in complexity (for these alternative models, the Akaike information criterion ranges from 398.8 to 457.0, as compared to 332.5 for the model including the constant term, random effect, and variable SITE).

\section{Qualitative analysis}

\subsection{Steps of the qualitative analysis}

The qualitative analysis focuses on the content of speeches that the participants made to explain their crossing decision. It is based on the identification of the arguments expressed in the speeches. Following the "grounded" approach of Glaser and Strauss (1967), the list of the topics of arguments was not developed before gathering and analyzing the data, but was generated from data. Thus, this list corresponds to participants' topics and not to topics $a$ priori defined by researchers.

An initial analysis was done on 9 interviews (three randomly taken from each group). It consisted in gathering the various arguments used by each of these 9 participants to explain his/her decision for each site without distinguishing arguments for "crossing" from arguments for "not crossing". A first categorization of arguments was drawn up in this way. It was general enough to be used for all groups and all sites and it made possible comparisons within 
and between groups. These categories of arguments dealt with elements of the environments and the situations either visible or deduced by the participants.

Afterwards, this first grid was refined progressively during the analysis of other interviews and a few sub-categories were added or changed. In the end 67 categories of arguments were obtained. They are related to five broad topics:

- $\quad$ the infrastructure and its features (22 categories of arguments);

- the environment: its features and inferences produced in terms of spatialization, "purpose" (predominance given or made to pedestrians or vehicles), speed limit, visibility (19 categories of arguments);

- the pedestrians, notably inferences about pedestrian density and behavior (frequency and type of crossing, attention to traffic) (11 categories of arguments);

- $\quad$ the traffic, particularly inferences in terms of density and behavior (speed, attention to pedestrian) (12 categories of arguments);

- $\quad$ the feelings of safety and danger of the participant (2 categories of arguments).

A sample of 36 interviews (taken from the whole set of 77 interviews ${ }^{1}$ ) was analyzed by four researchers involved in the project, using this analysis framework. These 36 interviews were randomly selected (12 interviews in each group). The distribution of the crossing decisions for the 36 individuals selected was compared to that of the whole sample, for the five sites. Table 4 shows that the proportion of positive decision (decision to cross) in each site is similar between the overall sample and the randomly selected sample.

\begin{tabular}{lcc}
\hline Site & Total sample & Sample for qualitative analysis \\
\hline Countryside environment & $12 \%$ & $8 \%$ \\
Commercial zone environment (outskirts) & $13 \%$ & $17 \%$ \\
Public housing environment (outskirts) & $19 \%$ & $22 \%$ \\
Inner suburb environment & $91 \%$ & $92 \%$ \\
City center environment & $34 \%$ & $36 \%$ \\
\hline
\end{tabular}

Table 4. Rate of crossing decision (answer = YES) in the total sample and in the sample randomly selected for the qualitative analysis

Then the categorized arguments from the 36 interviews were listed in a table for each site, and for each of the three groups of participants. Thus, it was possible $(i)$ to analyze the differences

\footnotetext{
${ }^{1}$ The extension of this thorough qualitative analysis to the whole set of 77 interviews would not have been feasible within the timescale of the project.
} 
between groups and (ii) to produce a synthetic view of the arguments for each site and analyze the differences between sites.

This analytical method led to a systematic, refined and objective coding of all the arguments used in the analyzed interviews. A return to the data source remained possible at each step as the method produced a gradual synthesis. Lastly, in addition to providing a list of arguments used, this method also allowed to explore the structure of arguments, their relationships and their representation for each group and each site.

\subsection{Production of inferences}

This qualitative analysis of discourses of the interviewed participants enabled to better understand the participants' decision to cross or not in each environment presented and the role of built environment in their decision. The first main explanation expressed by participants obviously dealt with the speed of the car. Considering the experimental protocol, the car's speed couldn't be estimated from cinematic data. It was in fact deduced from some cues directly took from the visible scene (roadway width, straight road alignment, etc.) but above all it was deduced from inferences concerning the situation (spatialization of the site, pedestrian density and movements, probable degree of expectation by drivers of pedestrians' presence) as presented in the next paragraph. These inferences were produced by the participants from the indices picked up from the environment as stated in the further paragraphs.

A large number of inferences were produced from each site, within the three groups, although it could be noticed that the preadolescent group gave less detailed inferences than the adult age groups. The main inferences developed by the participants dealt with the spatialization of the site, types of pedestrians' movements, density of pedestrians, expectation of pedestrians by the drivers, and attention paid by the drivers to the pedestrians. All these inferences were often mutually dependent and inferred the ones from the others. The links between inferences were often explicitly expressed, but they could also be more implicit, often expressed as a global formulation using labels.

\subsubsection{Use of labels}

Indeed, the qualitative analysis reveals firstly that the participants often used "labels" to qualify the site presented and to explain their decision to cross or not to cross. This use of "labels" was always spontaneous as such formulations have never been used by the experimenter, or even suggested. The designations most frequently used are: "countryside", 
"commercial zone", "industrial area", "residential precinct", "neighborhood", "residential zone", "city", "village" "downtown", "pedestrian zone". These "labels" seemed to be, for the participants, a comprehensive and integrated way to characterize a site: "This is a city that", "It's a commercial area", "we are in a residential precinct" "there is like a village". They were supposed to self-evidently explain some of the expected behavior in this place, without requiring further development, thereby producing inferences: "it must happen more slowly because we are in a kind of residence"; "This is a neighborhood so it is less crowded". These "labels" and related inferences were further explained, usually as a result of the experimenter's rephrasing or questioning of explanation.

In addition to the "labels" applied to sites as a whole, global order qualifiers were also attributed to the infrastructure: "it is a county or state road", "it is a country road", "clearly a national road", "it seems like a county road", "a fast-track", "a main street", "a quite common road'. These formulations, as well as the labels, were not explained, but seemed to be enough for the participants to justify inferred behaviors: "This is a large state road and certainly people drive very fast".

\subsubsection{The spatialization of the site presented}

The first important type of inference was indeed related to the spatialization of the site, i.e. the geographical location of the site in relation to the city center. The qualitative analysis showed that the opportunity to locate the environment presented in relation to the urban center seemed to be of importance for the individuals. They specified the closeness or distance from the center of the city: "it is not a center, it is more on the outskirts", "it is less the city center. Presumably it is not far from the city either, thus we may be around the city", "here it is the road out of a town, in the outskirts", "we are between the city and the countryside, a little further even", "It is not yet the city", "really within a city", "in the heart of downtown", "really in the center of the city", "it is out of the city", "not in the city center, [but] one of the streets a little more on the edge, not very far", "to go downtown". Spatialization brought inferences directly linked to the cars' speed ("that speeding, because it is out of town", "it's in town, she should not drive very fast") or intermediary inferences such as ones about pedestrian density and movements or traffic type and expectation of pedestrians by drivers.

\footnotetext{
${ }^{2}$ The quotes are excerpts from the 36 interviews analyzed, keeping the wording used by participants.
} 


\subsubsection{Inferences related to the pedestrians}

The second important type of inferences concerned the types of pedestrian movement, density of pedestrians, and balance of power between pedestrians and drivers. According to the participants, the speed of vehicles is also related to these types of inferences. In the environment of public housing, because the site was not perceived as a road for strolling, "not an area for taking a walk", participants anticipated high vehicle speed whereas inferring a high population density: "It's always a little bit the same reasons that can lead to less respect the speed limit; the less people there are, the more it is deserted, the more one may be tempted to go faster". The density of pedestrians is determined sometimes directly from the spatialization inferred: the farther you are from the city center, the less the environment is favorable to walk. For instance, in the public housing environment in the outskirts participants noted that "This is the kind of environment where you meet a lot of pedestrians", but "less than downtown". In some other cases, the density of pedestrians is determined through the density of human presence which is inferred according to the spatialization. In inner suburbs participants thought it was located "in suburban [environment]", in "a city where you go by car, but where you rarely live". It appears to be a "much quieter neighborhood", "calm". In addition to the density of pedestrians, the density of human presence also led to infer some types of pedestrians' movements. Thus, for the public housing site, participants inferred that "it is a heavily populated area" which led to anticipate frequent road crossings. In this site, some participants particularly inferred the presence of children "playing on the car parks", of "youth", and assumed the presence of establishments nearby producing a stream of young pedestrians: "a school", "a high school, a kindergarten, a nursery". According to young and middle adults, the presence of pedestrians varied depending on the time of the day: "Between noon and two, people who will pick up the kids at school; and in the early morning, to take them to school, and then in the evening after school or work. But I think after, during the day, there must be young people who are out, but not much".

However, the link between density of human presence in one hand and quantity of pedestrians and pedestrians' movements in the other hand seems to be equivocal. For some participants, the pedestrian density and movements were more related to the types of activities which take place in the environment rather than to the density of population living in the neighborhood. For them, the most important thing to consider was not the number of potential pedestrians due to the amount of population, but the presence of attractive activities for pedestrians to sojourn and to stroll in the environment. For instance, for the city center site, they considered that shopping activities brought a large number of pedestrians: "tobacconist means many 
movements", making it an "area where many pedestrians go there". Pedestrian behaviors mentioned were more diverse: "It is much more varied in terms of movement"; the pedestrian came "to wander", "to walk", "to go shopping", "to drink coffee". This stroll also influenced the street crossings: "there was much reason to cross" "at any time" and "anywhere". On the contrary, concerning the inner suburb site, some participants felt that "this is not a stoppingoff place", "not somewhere you'll stay", "not an environment to walk".

According to some participants, the type and quantity of pedestrians' movements are also inferred from the balance of power between drivers and pedestrians in the site. More or less frequent crossing movements, occurring in more or less regulated places, are inferred depending on both the type of activities and the degree to which the site appears to be intended for pedestrians. Thus, in the city center the participants noticed that "pedestrians feel they have priority" or "believe that everything is permitted. They cross anyhow"; the "people who are not very careful cross like that, without looking at the cars".

\subsubsection{Inferences related to the vehicles and drivers}

The third important type of inference concerned directly the vehicles and drivers, and more precisely the type of traffic, the expectation by the drivers of specific pedestrian behaviors and movements, and the attention paid by drivers to pedestrians. Participants inferred the traffic type according to the spatialization of the sites: distance from the city center went together with through-traffic rather than access traffic. Thus, the countryside site, because of its distance from the city center, was expected to bring a through-traffic: this site is used "to travel", according to some children, or to "go in or to leave the city", according to some young adults who thought that it might be two traffic peaks ("Those who come to work in the morning, and those who return in the evening at around 5 p.m.").

The expectation of pedestrians by the drivers was inferred from the density of pedestrians, and from the pedestrians' type of movement and behavior, that were also inferred as described in the previous subsection. For instance, in the commercial area, the majority of participants thought that the drivers did not expect a pedestrian crossing movement ("it is not expected that someone starts to cross like that, he [the driver] should never once think about it") because they mostly anticipated an average density of pedestrians related to specific behaviors of pedestrians: "there are not many people who walk", "fewer people walking", this type of environment was "not an area where people walk", "you do not do the shopping". In the public housing environment in the outskirts, some participants felt that drivers "expect to see people on the sidewalk but they don't expect that someone crosses in front of them like that. It 
is not advised. It is expected to cross at a crosswalk, not just in front of us". Some others participants inferred a greater expectation, by the drivers, of pedestrian crossing movements because of the high population density: "We know there is someone who can tumble right or left", or "the risk that a child arrives", "the usual story of the ball".

On this basis, they then inferred a greater or lower attention paid to pedestrian by the driver, which influenced the inferred speed of the vehicles. In the downtown area, for example, participants inferred a high level of attention of the driver from these heterogeneous pedestrian movements: "the oncoming vehicle, he knows he is entering a pedestrian area and expects to see pedestrians", "it should have a more moderate speed than on an empty road where it is not in town".

\subsection{Environmental cues}

As it has been shown previously, the inferences concerning pedestrians and drivers' behaviors, as well as global labels, were largely used by the participants to explain their crossing decision. These inferences and labels were necessarily deduced from environmental cues visible in the photographs. And participants expressed themselves concerning these environmental cues.

\subsubsection{Type of buildings}

One of the major cues used by participants was the presence, function, and configuration of the built environment. Spatialization (i.e. the geographical location of the site in relation to the city center) appeared specially inferred from the type of buildings (its function, but also the architectural aspects) and its concentration. Thus, for the inner suburb environment, participants noted that "the condition of housing [...] sounds more like downtown in fact. It is rather old". The type of buildings also led to infer the density of population living in the neighborhood, density of pedestrians, types of pedestrian movement, and attention paid by drivers to pedestrians. The qualitative analysis showed in particular that commercial buildings were a key element to infer the location of the site from the center of the city, and the pedestrian density and movements. But these inferences differed according to the configuration of the buildings. For instance, a high density of commercial activities in small shops - but not a high density of dwellings - was considered as a sign of high pedestrian density, heterogeneous pedestrian movements and high driver's attention towards pedestrians. Thus, on the site in the city center, most of the participants noted the presence of "shops", "restaurants", "terrace of cafe"" "grocery store", "street level of town houses converted in 
shops". They deduced that "There was much reason to go through, because people are going from one shop to the other, and cross", "at any time" and "anywhere". On the other hand, commercial activities in scattered supermarkets and large stores combined with a lack of dwellings led to infer a low density of pedestrians and crossings. Thus, in the commercial zone environment in the outskirts, the participants noticed the presence of numerous garages and various stores. They stressed the type of stores, which were supermarkets and big chain stores and not small shops: “it isn't stone buildings, it's sheet metal buildings that we can see all around and it's typical from commercial zone that have been built very quickly... the roofs are flat". Then they deduced a quite low density of pedestrians and don't expect pedestrians' crossing movements because "you don't shop".

\subsubsection{Presence and type of sidewalks}

Another key element was the presence and quality of the sidewalks. They were considered as a sign of pedestrian density and heterogeneous pedestrian movements, and a sign that they are taken into account by urban designers and planners. The width of the sidewalks, their height and delimitation from the roadway were used to deduce the "balance of power" between pedestrians and drivers, drivers' attention and yielding to crossing pedestrians. Thus, the site in the city center, which was equipped with wide and lowered sidewalks, was seen as "equipped for pedestrians". More precisely, the boundary between the sidewalk and the roadway led some middle-age adults to mention that "we may feel that we more share the road with cars. It really is reserved for pedestrians and cars at a time. Both share the road really together". According to middle-age adults, "pedestrians feel they have priority" in this type of environment. They "believe that everything is permitted. They go through anyhow". More generally, young and middle-age adults noted that "the pedestrians are in their element", "they feel in their environment, you know". The presence of pedestrian guardrails on the sidewalks of the inner suburb site was interpreted as a sign of the presence of pedestrians "metal guardrails give the idea that there will be pedestrians". Concerning the public housing site, the participants noted that "the sidewalk, well, it is not so small... but we see that it is only done to allow people to come and go in their homes or in their car". And referring to the countryside site as a whole and especially the lack of sidewalk, the participants stressed that "it is not for use by pedestrians", "it is not designed to receive pedestrians". 


\subsubsection{Presence of marked parking spaces}

The last key element was the presence of marked parking spaces. The strong presence of parking was often interpreted as a sign of motorized traffic rather than pedestrian traffic. The relationship between the number of parking spaces, on one hand, and the assumed density of traffic and potential vehicle maneuvers, on the other hand, especially appeared for the commercial zone in the outskirts: "[there is] a lot of parking spaces, so there is necessarily more cars that must park". Combining with the type of building, it led also to infer a low density of pedestrian and very few crossing movements. A large number of marked parking spaces was interpreted as an indication that the pedestrian movements focus on the routes between vehicles and homes. It is also the case in public housing environment in the outskirts: "It is rather a place where people go when they want to go back home, they park and they go up [in the building], "they take their car and they go ... either you go home, or you leave". On the contrary, the lack of parking seemed interpreted as evidence of the many pedestrian movements. Thus, in the case of the city center, the lack of marked parking places led participants to infer a low traffic density: "cars they come not here, knowing they cannot stand to stop buying ... I do not know... bread! So automatically there is much less traffic". This low traffic density was accompanied by a high density of pedestrians "when visiting the shops, we do not find much space in the city center [to park], you have to stop in the parking area and after walking on foot".

\subsection{From environmental cues to crossing decision}

All of these elements helped to understand the differences in the decision-making of crossing in the different environments. In their interviews, the participants expressed inferences or series of inferences from environmental cues, in order to explain their decision to cross or not to cross. Some observable elements in the photographs led them to deduce some non-visible information that they then used to infer some other information used to make a decision. These series of inferences and arguments are schematically represented in table 5. The results presented in table 5 should not be considered as a model of the crossing decision process, but rather as indicative of the various ways the environment may influence crossing decisions. Thus, the visible cues presented on the photographic material - such as the presence and quality of the sidewalks, marked parking spaces, type and function of the buildings - allowed participants to characterize the site presented in a synthetic way, generally in the form of an environmental label, and permitted them to infer a distance of the site presented from the center of the city. According to the label and the spatialization inferred and to the visible 
environmental cues, the participants produced new inferences about the uses of the site presented, in terms of pedestrians' movements and density, traffic density, and average speed of traffic. From these first produced inferences, information concerning the relationship between the different types of users of the environment was deduced, especially the driver's degree of expectation of the pedestrians' presence and the balance of power between cars and pedestrians in the environment presented. All this deduced general information on the functioning of the site were then used by the participants to produce more contextual inferences related to the situation of crossing itself. These contextual inferences particularly focused on the attention paid to this particular pedestrian waiting to cross by the driver of the vehicle visible on the photograph, as well as the assumed vehicle speed as a function of these different elements, this last element being the first piece of information the participants gave to explain their decision to cross or not in the situation presented.

\begin{tabular}{|c|c|c|c|c|c|}
\hline \multirow{3}{*}{$\begin{array}{l}\text { Environmental } \\
\text { cues }\end{array}$} & \multicolumn{4}{|c|}{ Inferential chains } & \multirow{3}{*}{$\begin{array}{l}\text { Results of the } \\
\text { inferences }\end{array}$} \\
\hline & \multicolumn{3}{|c|}{ General inferences } & \multirow{2}{*}{$\begin{array}{c}\begin{array}{c}\text { Contextual } \\
\text { inferences }\end{array} \\
\text { Specific } \\
\text { crossing } \\
\text { situation }\end{array}$} & \\
\hline & $\begin{array}{c}\text { Synthetic } \\
\text { characterization }\end{array}$ & Types of use & $\begin{array}{c}\text { Relationship } \\
\text { between the } \\
\text { users }\end{array}$ & & \\
\hline $\begin{array}{l}\text { Parking } \\
\text { spaces }\end{array}$ & Labels & $\begin{array}{l}\text { Pedestrian } \\
\text { density } \\
\text { Pedestrian } \\
\text { movements }\end{array}$ & $\begin{array}{c}\text { Balance of } \\
\text { power } \\
\text { between cars } \\
\text { and } \\
\text { pedestrian }\end{array}$ & $\begin{array}{l}\text { Speed of the } \\
\text { approaching } \\
\text { vehicle }\end{array}$ & \multirow[b]{2}{*}{$\begin{array}{l}\text { Decision to } \\
\text { cross or not }\end{array}$} \\
\hline $\begin{array}{l}\text { Type and } \\
\text { function of the } \\
\text { buildings }\end{array}$ & Spatialization & $\begin{array}{l}\text { Amount of } \\
\text { traffic }\end{array}$ & $\begin{array}{l}\text { Degree of } \\
\text { expectation } \\
\text { (by drivers) of } \\
\text { the presence } \\
\text { of pedestrians }\end{array}$ & $\begin{array}{c}\text { Attention paid } \\
\text { by this driver } \\
\text { to this } \\
\text { pedestrian }\end{array}$ & \\
\hline
\end{tabular}

Table 5. Schematic representation of the inferences and chains of inferences found in the participants' discourse

Thus, the site labeled as "city center" was clearly different from the others in terms of crossing decision. According to the participants, this site is characterized by the presence of various convenience shops, in a road without marked parking spaces, equipped with large lateral spaces clearly dedicated to pedestrians (identified by participants as sidewalks). These mentioned elements were connected to inferences made by the individuals on the location of 
this site near the center of the city, the high density of pedestrians, and diversified pedestrian movements (particularly in terms of frequency and location of crossing movements). And this density and diversity of pedestrian movements were viewed as causing a strong attention from the drivers, itself resulting in low traffic speed. These elements could explain why the majority of participants answered they would have decided to cross in the city center site that has been presented to them.

In contrast, the site generating the fewest crossings, labeled as the countryside site, is characterized by the participants, by a lack of shops, a small number of houses, a wide pavement, without sidewalks or lateral space dedicated to pedestrians and without marked parking places. From these visible elements, participants inferred a low density of pedestrians and presence of through-traffic with high speed, due to a lack of anticipation by drivers of the presence of pedestrians in this environment. These elements could explain why the majority of participants answered they would have decided not to cross in the countryside site presented.

\section{Discussion}

This research aimed to explore the nature of perceptions of the built environment of crossing - both in terms of general feeling (pleasantness, feeling of safety) and in terms of road potentiality to be crossed - and their mobilization by the pedestrians when crossing. The results presented showed that pedestrians' perceptions of the pleasantness and safety of public spaces, in terms of walking, largely vary with urban environments. In particular, the site in city center environment was judged to be pleasant for walking, whereas other sites in public housing or commercial environments in the outskirts have low scores of pleasantness. The feeling of safety (for walking) seems to progress from the countryside environment ${ }^{3}$ to the outskirts environments first, and then to the inner suburb environment and the city center environment. As regards the crossing decisions, significant differences between environments are also found: the probability to cross was high in the city center environment, perceived as pleasant and safe, moderate in the public housing environment in the outskirts, and low for the other sites. These effects cannot be mainly attributed to the roadway width, since all the sites presented to the participants were sites with a two-lane roadway (one in each direction), nor to

\footnotetext{
${ }^{3}$ It is not sure that the low feeling-of-safety score of the countryside environment would have been different if the approaching vehicle had been placed at a larger distance on the photograph, since the question asked to participants was not related to the possibility to cross but was more general: "To what extent would you find it safe to walk in this environment?"
} 
the particular traffic situation, since the only vehicle present in the vicinity, visible on the left photographs, was always located at the same distance from the point of observation. The low probability to decide to cross in the countryside environment is not surprising, and suggests that this site is easily identified as a rural site with a higher level of speed, for which the distance to the vehicle $(35 \mathrm{~m})$ corresponds to a short time gap. However, large differences appear (in terms of probability to decide to cross) between the other environments, which are all urban and with a legal speed limit of $50 \mathrm{kph}$. The qualitative analysis of the interviews provided some explanations of these results. The principal element used by participants to explain their road crossing decision is the speed of vehicles. As photographs cannot directly inform on the movements of vehicles, the speed of vehicles was deduced from different elements: the characteristics of infrastructure and built environment that were directly available in the visual scene, and elements inferred by the participants from the built environment (such as the traffic and pedestrian density, pedestrians' behaviors, drivers' attention and expectancies, and site location from the center of the city).

The goal of the study was also to explore the influence of driving experience on the link between built environment and crossing decisions, by comparing three distinct age groups. In terms of results, quantitative analysis of data showed that children's crossing decisions did not significantly differ from those of the two other groups. Qualitative analysis of speeches showed, however, that children differed from adults in their use of labels and spatialization, which were often less precise and less frequent among children than among both others groups. This could be linked with the lower experience of urban environments and, obviously, with the lack of driving experience among children. It might be interesting to explore how the representation of different types of built environments and their spatial organization grows with age and what are the determinants of this evolution. Moreover, how the classifications of built environment become more and more diverse and complex with age, particularly under the influence of pedestrian and driver mobility, should be explored. Furthermore, complementary studies on the representation of built environments and its role in crossing decision among older people would also be needed, since this age group is particularly involved in pedestrian accidents (ONISR, 2011). Due to its particularities, for example in terms of functional limitations (Dommes et al., 2013), this age group was not considered in the present work. However, it would be important to understand how the crossing environment is taken into account by the older pedestrians, including how it influences the inferences they make on the balance of power between pedestrians and drivers and on the driver's behavior. 
This study suggests that pedestrians use spatialization of the site in their crossing decision. The role of spatialization (relatively to the city center) was already shown by Montel et al. (2004), in their study on drivers' categorization of urban road environments. The site location in the city seems to constitute a structuring element that determines how the drivers categorize urban roads. It seems that pedestrians, as drivers, refer to a centered perception of the city and that the location of the streets according to this representation plays an important role in the organization of the knowledge that pedestrians and drivers judge to be relevant in their decision making.

Furthermore, the experiment confirms the participants' extensive use of "labels", as shown in a previous study by the method of focus groups (Granié et al., 2013). These labels appeared to be directly related and interacting with spatialization, cues from the environment, and inferences concerning traffic speed and density of pedestrians and vehicles. These various elements seem to be aggregated by the participants into classes of situations (referred to by using labels), referring to their experience. With reference to research on cognitive categories and the notion of prototype, made in line with the work of Rosch (see in particular Dubois, 1991; Rosch, 1978; Rosch and Mervis, 1975), and its applications to road spaces (Dubois et al., 1993; Mazet et al., 1987; Montel et al., 2004), the participants' use of labels could be interpreted as reflecting the use of knowledge in memory, and suggests in particular that these labels are related to knowledge structured in mental categories and formed within the framework of a particular activity (in this case, the activity of travel and practice of public space). Such categories correspond to a need for cognitive economy (Rosch, 1977) and are inseparable from the context of their production and their use, and therefore from behavioral responses in the real world. Furthermore, discrimination between road scenes are not made solely on the basis of perceptual regularities but also from actions that these situations lead road users to develop (Dubois et al., 1993). It has thus been shown that the representations of the road environment induce driver's expectations about the future presence of other types of users, even if they are not initially present in the scene presented (Fleury et al., 1991).

Moreover, these expectations vary, depending on the context of driving such as the time of the day (Montel et al., 2004). Thus, the inferences made by the participants may be the product of the expectations about the behaviors of the other road users in a specific road environment, as gradually built from the previous experience of the participants in various situations. From this point of view, the labels used could depend on the experience of participants, which can explain the differences detected between children and adults in the qualitative analysis. It cannot be excluded, however, that the labels may just be summaries used in the participants' 
discourse, and do not reflect the existence of categorical representations in memory. The accumulation of experience would then enhance the capacity to (or need to) use such discursive statements. However, it remains to better understand the factors governing the inferences that are produced from the environment. Indeed, the results show that all individuals do not make the same crossing decision and do not produce the same inferences from the same environmental cues. These differences should be investigated, notably as regards the respective influence of psychological factors (Granié, 2009; Moyano Diaz, 2002; Yagil, 2000), of life experiences (Fleury et al., 2010; Licaj et al., 2011), and of representations and stereotypes associated with certain environments (Blokland, 2008; Rosenbaum et al., 2002).

Moreover, it should be noted that the arguments used to justify the decision mainly refer to a "car-oriented" reading of the environment, whatever the site. Thus, pedestrians, in their analysis of the environment, seem to be mainly looking for clues to understand what their place is in this environment and to assess the balance of power between them and the drivers. This tendency to focus on the driver, often with a negative a priori which leads to defensive behavioral strategies, has already been shown in young pedestrians (Granié and Espiau, 2010; Platt et al., 2003) and among cyclists (Van Schagen and Brookhuis, 1994). This can be interpreted as a manifestation of social identity, i.e. a membership in an identified and differentiated particular social group. Thus, it has been recently shown that the status occupied by an individual in the road space - yet labile status in space and time - can lead to attitudes that express belonging to a social group of users (pedestrian, cyclist, driver): devaluation of the out-group and valorization of the in-group (negative perception of driver behavior, for example, when traveling as a pedestrian) (King et al., 2012). This focus on a car-oriented reading of the public space can also be due to the situation in which the individual was placed in this study, i.e. a situation of crossing and therefore of potential interaction with moving vehicles and may not be found in the pedestrians' reading of environment outside the crossing task. It is also possible that the composition of the sample itself, recruited in a highly motorized and little pedestrianized area is also at the origin of this focusing. This interpretation of a centering on the threatening aspects of the environment in the pedestrian's use of the environmental cues for the crossing decision should be verified on a more urbanized and pedestrianized sample. This question is all the more important that current approaches in Europe go in the direction to make the least vulnerable users more aware and responsible vis-à-vis the most vulnerable road users, especially at road crossings. 
This therefore suggests implementing strong actions to reverse the historical trend which favors motorized modes and users, to the new benefit of vulnerable users.

\section{Limitations of the study}

Some limitations of the study have to be pointed out. It should indeed be taken into account that the context of the crossing, such as the motivation or the urgency to join the other side of the street, obviously influences the behavior and the decision-making (Charron et al., 2012). In the study presented here, the imposed objective to cross the road could have influenced the participants in different ways, depending on the site. The differentiation made by the participants between the various urban environments presented could thus have been linked to the appropriateness of the crossing objective to the site, rather than to the features of the environment.

Furthermore, in terms of methodology, some points can be drawn from this experiment. First, the results show that, despite the discrepancy between the situation in which the participants are placed and the real-life situation of street crossing decision, the use of photographic material, static by definition, proved relevant to access the influence of factors related to the environment and inferences produced on this basis. Indeed, it helped to neutralize the elements of decisions related to kinematic aspects (including the approach speed of the vehicle), the ambience (including noise) and the interaction between driver and pedestrian that could significantly influence decision making, but would also obscure the influence of factors related to the environment in the explanation given by the participants. In continuation of this study, it would obviously be necessary to confront the pedestrian to dynamic scenes, in a dual purpose. It would indeed be necessary to identify the contribution of the dynamic elements in comparison with the static elements, in the construction of inferences and in the influence of the built environment on the decisions. It would then be needed to study the influence of the built environment in the context of real crossing situation, while including both cognitive and psychomotor aspects in decision making.

Secondly, the technique of interview used in this experiment, based on Piaget's clinical technique was found to be effective. Through the use of follow-ups and counter-suggestions, it allowed the participants to best explain all the elements they used and inferred from the proposed materials to make the decision to cross or not. The number of inferences produced by the participants shows that the experimental protocol favored explanation by individuals of their representations of environments and suggests that, in general, pedestrians use, consciously or not, a certain amount of information they deduce from the elements present in 
the scene in everyday situations of crossing decision. These findings help to understand the role played by the environment in the crossing decision process, but the extent to which such inferential chains represent the way crossing decisions are made in the real world remains uncertain; they could also be interpreted at least partially as rationalization in hindsight. Furthermore, the difficulty of the interview using this technique also comes from its richness: it is obvious that some of the differences observed between groups in the qualitative analysis are due to differences in the level of development of the language among the participants (Bruner, 1983), especially between the group of children and the adult groups. Moreover the children have also less expertise about road environments, causing difficulty of explaining their decisions in the various situations.

\section{Conclusions}

In brief, the quantitative and qualitative analyses showed that some key elements in the broad environment are used by participants to deduce some information which influences crossing decisions. This study thus validates the hypothesis that built environment influences pedestrians' crossing decision. The results also suggest that the perceived pleasantness and feeling of safety are not sufficient to understand the effect of the built environment on crossing decisions.

Some elements of built environment and public space design (especially the function of the buildings, presence and type of commercial activity, width of sidewalks, and presence of marked parking spaces) are used by pedestrians to infer the pedestrian and traffic density, attention to pedestrians, and speed of vehicles, and then to decide to cross or not. Thus, the options chosen in terms of urban planning and design are not without consequence and influence the way pedestrians interpret and use public spaces and the way they make decision to cross urban roads. This provides food for planners and road engineers, whose present challenge is to take all users into account when designing public spaces, and this underlines the necessity for them to consider the environment. This meet the principle of "complete street" that aims to take all road users into account but that is designed depending on surroundings (Smith et al., 2010).

The results also suggest that pedestrians heavily refer to the spatialization of the site (relatively to the city center) and the balance of power between pedestrians and cars when they develop inferences and decide to cross or not. This also provides food for thought on how to implement certain contemporary road engineering concepts such as the "zones de rencontre" used in Switzerland, Belgium and France, or similar concepts in other European 
countries ("verkehrsberuhigter Bereich", "erf", "living street”, for example). The principle of these concepts is based on the totally mixed use of road and public space by all categories of users, and on giving priority to pedestrians over vehicles, including motor vehicles. An assessment of such layouts from the pedestrian's point of view would be useful to determine how pedestrians perceive them and identify their "territory", which is supposed to be shared by all travel modes, in this situation.

The conclusions to be drawn from these results for urban design and planning, however, should be cautious. The results have been obtained from European participants, confronted with a few European urban environments, which represent a variety of urban contexts but are not representative of all the diversity of urban environments. Urban fabrics in other countries can be rather different from those encountered in Europe. Moreover, some urban environments or some features of public space or urban organization improve the pleasantness and feeling of safety for pedestrians but that does not mean that such environments or design options necessarily improve their actual safety. Further research is needed in order to study how the various urban environments are understood and interpreted by drivers (see for example (Montel et al., 2005), especially as regards pedestrians, and to evaluate their actual levels of safety.

\section{Acknowledgements}

The present research was funded by the French Foundation for Road Safety and the French Directorate for Road Safety and Traffic.

An earlier shorter version of this paper was presented at the Transportation Research Board 92nd Annual Meeting, Washington, D.C, USA, January 2013.

\section{References}

Aarts, L., Van Schagen, I., 2006. Driving speed and the risk of road crashes: A review. Accident Analysis \& Prevention 38, 215-224.

Ananth, C.V., Platt, R.W., Savitz, D.A., 2005. Regression models for clustered binary responses: implications of ignoring the intracluster correlation in an analysis of perinatal mortality in twin gestations. Annals of Epidemiology 15 (4), 247-320.

Baranes, C., Letellier, A., Pannerer, C.L., Pirot, V., 2005. Flux automobile et sécurité pour les piétons. Rapport final de recherche sur subvention PREDIT GO3 / DRAST. Magistram, Paris.

Bergeron, J., Cambon de Lavalette, B., Tijus, C., Poitrenaud, S., Leproux, C., Thouez, J.P., Rannou, A., 2008. Effets des caractéristiques de l'environnement sur le comportement des piétons à des intersections urbaines. In: Granié, M.A., Auberlet, J.M. eds. Le piéton et son environnement. 
Quelles interactions? Quelles adaptations ? Actes INRETS n ${ }^{\circ} 15$. Collection INRETS, Paris, pp. $163-174$.

Blokland, T., 2008. "You Got to Remember you Live in Public Housing": Place-Making in an American Housing Project. Housing, Theory and Society 25 (1), 31-46.

Bruner, J.S., 1983. Child's talk: learning to use language. Oxford University Press, Oxford.

Charron, C., Festoc, A., Guéguen, N., 2012. Do child pedestrians deliberately take risks when they are in a hurry? An experimental study on a simulator. Transportation Research Part F: Traffic Psychology and Behaviour 15, 635-643.

Cho, G., Rodriguez, D.A., Khattak, A.J., 2009. The role of the built environment in explaining relationships between perceived and actual pedestrian and bicyclist safety. Accident Analysis \& Prevention 41, 692-702.

Chu, X., Guttenplan, M., Baltes, M.R., 2004. Why People Cross Where They Do. The Role of Street Environment. Transport Research Record: Journal of the Transportation Research Board. Transportation research Board of the National Academies, Washington, D.C., pp. 3-10.

Clifton, K.J., Burnier, C.V., Akar, G., 2009. Severity of injury resulting from pedestrian-vehicle crashes: What can we learn from examining the built environment? Transportation Research Part D () 14 425-436.

Davis, G.A., 2001. Relating severity of pedestrian injury to impact speed in vehicle-pedestrian crashes, simple threshold model. Transportation Research Record 1773, 108-113.

Dissanayake, D., Aryaija, J., Wedagama, D.M.P., 2009. Modelling the effects of land use and temporal factors on child pedestrian casualties. Accident Analysis \& Prevention 41 (5), 1016-1024.

Dommes, A., Cavallo, V., Oxley, J., 2013. Functional declines as predictors of risky street-crossing decisions in older pedestrians. Accident Analysis \& Prevention 59 (0), 135-143.

Dubois, D., 1991. Sémantique et cognition. Editions du CNRS, Paris.

Dubois, D., Fleury, D., Mazet, C., 1993. Représentations catégorielles, perception et/ou action? Contribution à partir d'une analyse de situations routières. In: Weill-Fassina, A., Rabardel, P., Dubois, D. eds. Représentations pour l'action. Octarès Toulouse, pp. 79-93.

Ewing, R., Handy, S., Brownson, R.C., Clemente, O., Winston, E., 2006. Identifying and measuring urban design qualities related to walkability. Journal of Physical Activity and Health 3 (suppl. 1), S223-S240.

Fleury, D., Dubois, D., Fline, C., Peytavin, J.F., 1991. Catégorisation mentale et sécurité des réseaux. Rapport Inrets $n^{\circ} 146$. Inrets, Arcueil.

Fleury, D., Peytavin, J.F., Alam, T., Brenac, T., 2010. Excess accident risk among residents of deprived areas. Accident Analysis and Prevention 42 1653-1660.

Foltête, J.-C., Piombini, A., 2007. Urban layout, landscape features and pedestrian usage. Landscape and Urban Planning 81 (3), 225.

Foot, H.C., Thomson, J.A., Tolmie, A.K., Whelan, K., Morrison, S., Sarvary, P., 2006. Children's understanding of drivers' intentions. British Journal of Developmental Psychology 24, 681-700. 
Glaser, B.G., Strauss, A.L., 1967. The discovery of grounded theory: strategies for qualitative research. Aldine, Chicago.

Graham, D.J., Glaister, S., 2003 Spatial Variation in Road Pedestrian Casualties: The Role of Urban Scale, Density and Land-use Mix Urban Studies 40 (8 ), 1591 - 1607.

Granié, M.A., 2009. Effects of gender, sex-stereotype conformity, age and internalization on risktaking among adolescent pedestrians. Safety Science 47 (9), 1277-1283.

Granié, M.A., Espiau, G., 2010. Etude qualitative du comportement piéton de collégiens par la méthode de l'autoconfrontation. Territoires en Mouvement 2008 (1), 39-57.

Granié, M.A., Montel, M.-C., Brenac, T., Coquelet, C., Millot, M., Monti, F., Pannetier, M., 2013. Qualitative analysis of pedestrians' perception of the urban environment when crossing streets. Advances in Transportation Studies XXXI, 17-34.

Hine, J., 1996. Pedestrian travel experiences. Assessing the impact of traffic on behaviour and perceptions of safety using an in-depth interview technique. Journal of Transport Geography 4 (3), 179-199.

King, M.J., Wood, J.M., Lacherez, P.F., Marszalek, R.P., 2012. Optimism about safety and groupserving interpretations of safety among pedestrians and cyclists in relation to road use in general and under low light conditions. Accident Analysis and Prevention 44 154- 159.

Li, L., Yang, X., Yin, L., 2010. Exploration of Pedestrian Refuge. Effect on Safety Crossing at Signalized Intersection. Transport Research Record: Journal of the Transportation Research Board. Transportation research Board of the National Academies, Washington, D.C., pp. 44-50.

Licaj, I., Haddak, M., Pochet, P., Chiron, M., 2011. Contextual deprivation, daily travel and road traffic injuries among the young in the Rhône Département (France). Accident Analysis and Prevention 43, 1617-1623.

Livi Smith, A., 2009. Contribution of Perceptions in Analysis of Walking Behavior. Transportation Research Record: Journal of the Transportation Research Board 2140, 128-136.

Lobjois, R., Cavallo, V., 2007. Age-related differences in street-crossing decisions: the effects of vehicle speed and time constraints on gap selection in an estimation task. Accident Analysis \& Prevention 39, 934-943.

Marshall, W.E., Garrick, N.W., 2010. Effect of street Network Design on Walking and Biking. Transport Research Record: Journal of the Transportation Research Board. Transportation Research Board of the National Academies, Washington, D.C., pp. 103-115.

Mazet, C., Dubois, D., Fleury, D., 1987. Catégorisation et interprétation des scènes visuelles: le cas de l'environnement urbain et routier. Psychologie Francaise 32 (1/2), 85-95.

Millot, M., 2008. Projet urbain et sécurité des déplacements. Exemple de 4 quartiers en rénovation urbaine. Rapport final de recherche CETE Méditérrannée; commanditaire CERTU/DSCR. CERTU, Lyon.

Mitra, R., Buliung, R.N., Roorda, M.J., 2010. Built Environment and School Travel Mode Choice in Toronto, Canada. Transport Research Record: Journal of the Transportation Research Board. Transportation research Board of the National Academies Washington, D.C., pp. 150-159. 
Montel, M.-C., Nachtergaële, C., Michel, J.-E., Brenac, T., Van Elslande, P., 2004. Voies urbaines: représentations et attentes des conducteurs de jour, de nuit et en soirée. les collections de l'Inrets, Arcueil.

Montel, M.-C., Van Elslande, P., Brenac, T., 2005. Categorisation of streets by drivers and associated expectancies: a cognitive analysis of driving activity for safer urban design. Advances in Transportation Studies 7, 23-38.

Montel, M.C., Brenac, T., Granié, M.A., Millot, M., Coquelet, C., 2013. Urban environments, pedestrian-friendliness and crossing decisions. In: Proceedings of the Transportation Research Board 92nd Annual Meeting, Washington, D.C.

Moyano Diaz, E., 2002. Theory of planned behavior and pedestrians' intentions to violate traffic regulations. Transportation Research Part F: Traffic Psychology and Behaviour 5 (3), 169-175.

Mullan, E., 2003. Do you think that your local area is a good place for young people to grow up? The effects of traffic and car parking on young people's views. HEALTH \& PLACE 9 (4), 351-360.

ONISR, 2011. La sécurité routière en France: bilan de l'année 2010. Préédition. La Documentation Française, Paris.

Opper, S., 1977. Piaget's clinical method. Journal of Children's Mathematical Behavior 1 (4), 90-107.

Pitt, R., Guyer, B., Hsieh, C.-C., Malek, M., 1990. The severity of pedestrian injury in children: an analysis of the pedestrian injury causation study. Accident Analysis \& Prevention 22 (6), 549-559.

Platt, C.V., Clayton, A.B., Pringle, S.M., Butler, G., Colgan, M.A., 2003. Road safety education for children transferring from primary to secondary school. Road Safety Research Report $n^{\circ} 35$. Department for transport, Londres.

Rosch, E., 1977. Human categorization. In: Warren, N. ed. Studies in cross-cultural psychology. Academic Press, London, pp. 1-49.

Rosch, E., 1978. Principles of categorization. In: Rosch, E., Lloyd, B.B. eds. Cognition and categorization. Erlbaum, Hillsdale (NJ), pp. 27-48.

Rosch, E., Mervis, C.B., 1975. Family ressemblances: studies in the internal structure of categories. Cognitive Psychology 7, 573-605.

Rosén, E., Stigson, H., Sander, U., 2011. Literature review of pedestrian fatality risk as a function of car impact speed. Accident Analysis and Prevention 43, 25-33.

Rosenbaum, J.E., Reynolds, L., Deluca, S., 2002. How Do Places Matter? The Geography of Opportunity, Self-efficacy and a Look Inside the Black Box of Residential Mobility. Housing Studies 17 (1), 71-82.

Shay, E., Fan, Y., Rodriguez, D.A., Khattak, A.J., 2006. Drive or Walk? Utilitarian Trips Within a Neotraditional Neighborhood. Transport Research Record: Journal of the Transportation Research Board. Transportation research Board of the National Academies, Washington, D.C., pp. 154-161.

Smith, R., Reed, S., Baker, S., 2010. Street design: Part 1 - Complete street. Public Roads 74 (1), 1217.

Underwood, J., Dillon, G., Farnsworth, B., Twiner, A., 2007. Reading the road: the influence of age and sex on child pedestrians' perceptions of road risk. British Journal of Psychology 98, 93-110. 
Van Elslande, P., 2001. Dynamique des connaissances, catégorisation et attentes dans une conduite humaine située. L'exemple des " erreurs accidentelles " en conduite automobile. Thèse de Doctorat. Paris V Descartes.

Van Schagen, I.N., Brookhuis, K.A., 1994. Training young cyclists to cope with dynamic traffic situations. Accident Analysis \& Prevention 26 (2), 223-230.

Wedagama, D.M.P., Bird, R.N., Metcalfe, A.V., 2006. The influence of urban land-use on nonmotorised transport casualties. Accident Analysis and Prevention 38 1049-1057.

Yagil, D., 2000. Beliefs, motives and situational factors related to pedestrians' self-reported behavior at signal-controlled crossings. Transportation Research Part F: Traffic Psychology and Behaviour 3 (1), 1-13. 